\title{
Considerações Sôbre o Recrutamento e a Formação Profissional do Pessoal do Estado
}

\author{
PAUL-Victor Collin \\ Tradução de Lygia AzEvedo
}

$\mathrm{U}$

MA boa administração exige pessoal qualificado, principalmente dirigentes de elite. Uma rigorosa seleção inicial dará excelentes executores, não, necessàriamente, chefes. Os postos de direção só devem ser ocupados por pessoas que, além das qualidades naturais requeridas pela função de comando, tenham formação profissional adequada às tarefas a desempenhar.

O Exército de há muito compreendeu esta verdade e em todos os países existe, hoje, quaisquer que sejam sua denominação e estrutura, uma escola de guerra, uma escola militar, sem falar das escolas especializadas que formam tanto oficiais superiores como subalternos. A Administração, no entanto, salvo alguns esforços esporádicos e isolados, durante muito tempo quase não cogitou da educação profissional de seus servidores. Do mesmo modo, os critérios de recrutamento nem sempre se revelaram os mais adequadcs para selecionar os melhores para o serviço público.

Fenômeno que se verifica em todos os países, não é possível, em um pequeno estudo, examinar a evolução do recrutamento e a formação dc's servidores do Estado em cada um dêles. Seja-me, permitido, pois, nestas considerações, referir-me principalmente à Inglaterra, à França e à Bélgica e, incidentalmente, a um outro qualquer país. Mutatis mutandis, e levadas em consideração as peculiaridades de cada povo, o problema se equaciona de maneira análoga e pode resolver-se de modo idêntico.

\section{II}

Em 1850, a Inglaterra encontrava-se em plena crise de crescimento. O progresso da máquina impunha uma alteração da estrutura social; a burguesia industrial e comerciante tomava a frente à nobreza. Os novos senhores, os que se apoderaram das rédeas de direção do Estado, exigiam a reforma da administração pública. Entendiam êles que o Civil Service se tornara um ninho de funcionários incompetentes em conseqüência da maneira arbitrária pela qual era feito o recrutamentc, o que tornava difícil a promoção por antiguidade pela impossibilidade de caracterizar o tempo de serviço. Além disso, parecia-lhes que o Estado devia, dali em diante, adotar os métodos de gestão que faziam a grandeza da indústria. 
Face a essas queixas, o Parlamento encarregou o historiador MACAULAY de recrganizar o Civil Service, reorganização que produziu seus efeitos até a guerra de 1940.

Qual a estrutura da administração britânica?

Civil Service é o nome que se dá ao conjunto de administradores civis e empregados remunerados pelo Estado. Esta definição exclui, portanto, os militares, os membros do magistério e cs funcionários das municipalidades.

Divide-se o Civil Service em quatro classes (ou categorias) correspondendo à importância das funções e aos conhecimentos que elas exigem:

$\left.1 .^{\circ}\right)$ a administrative class abrange os funcionários que ocupam cargos de direção (administrative civil servants) nos diversos departamentos ministeriais;

$\left.2 .^{\circ}\right)$ a executive class agrupa os empregados responsáveis pela informação de processos e execução dos trabalhos administrativos;

$3 .^{\circ}$ ) a clerical class compreende o pessoal pròpriamente burocrático (escriturários, auxiliares administrativos, etc. );

$\left.4 .^{\circ}\right)$ a copying and shorthand class inclui essencialmente $c$ pessoal dos serviços auxiliares (dactilografia, estenografia, comunicações, etc.).

Como se pode verificar, êste sistema de classificação do pessoal do Estado assemelha-se ao adotado pela Bélgica quando da reforma administrativa de 2 de outubrc de 1937. M. LouIs CAMU, Comissário Real para essa reforma, evidentemente se inspirou no regime britânico. A subdivisão do pessoal do Estado em quatro categorias oferece, aliás, a vantagem de corresponder ao têrmo dos estudos nos diferentes graus de ensino em vigcr na Bélgica (ensino primário, ensinos médio inferior e médio superior e ensino superior).

$\mathrm{Na}$ ocasião em que Lord MACAULAY empreendeu a reorganização que the fôra confiada, não sòmente as ccndições de nascimento dos candidatos desempenhavam papel importante no recrutamento dos funcionários civis, como também pedidos e arranjos de tôda espécie concorriam para modificar o resultado dos concursos de admissão. Visando a corrigir êsses abusos, decidiu-se recorrer, de futuro, a open competition ou concurso acessível a todos, baseado em critérios experimentais prèviamente estabelecidos. A finalidade dessa "competiçãc aberta" é selecionar os candidatos cuja capacidade melhor corresponda aos cargos a serem providos.

Teòricamente ideal, êsse sistema, exageradamente fundado em bases escolares, foi responsável durante longos anos pela existência de classes sociais no seio da Administração inglêsa.

Até à primeira guerra mundial, os administrative civil servants provinham quase exclusivamente das camadas mais altas da sociedade. Faziam seus estudos primários e secundários nas Public Schools, as quais, ao contrário do que sua denominação faria supor, não são escolas públicas, mas sim estabelecimentos de ensino privados de nível muito elevado. Depois, matriculavam-se nas grandes universidades, Oxford e Cambridge de preferência, e ao fim do 
curso encontravam-se, então, aptos a prestar o concurso de admissão à administrative class do Civil Service.

Como as Public Schools se dedicavam mais a formar o caráter do aluno do que a desenvolver-1he a capacidade intectual, pois sua principal preocupação era fazer um gentleman, de 1854 a 1918 o concurso de admissão à classe administrativa dirigente visava sobretudo a aferir a cultura geral, ou mais exatamente, a general ability dos candidatos.

Democrático no sentido de que cada um podia prestar o concurso de admissão na categoria correspondente aos estudos realizados, o sistema Macaulay, no entanto, revelou tendências aristccráticas, eis que, na prática, reservava os cargos de primeira categoria para os filhos de famílias das classes dirigentes e, desde 1874, já o Chanceler do Erário desencorajava a transferência de uma classe para outra e proibia formalmente a constituição de qualquer associação de funcionárics.

O pessoal das classes inferiores do Civil Service, geralmente recrutado de acôrdo com critérios de base escolar, permanecia às mais das vêzes estagnado em sua categoria. Principalmente no que se refere à executive class, cujos funcionários saíam, em sua maioria, das Secondary Schools, raros eram os que logravam acesso à administrative class.

A guerra de 1914-1918 desfechou o primeiro golpe no tradicionalismo do Civil Service. Se o recrutamento para a administrative class permanece ainda subordinado aos princípios vigentes na era vitoriana e a maior parte dos candidatos tem por possuir um diploma universitário (bachelor of Arts, of Economic Sciences etc. ), nem todos saem mais das Public Schools; a elas também têm acesso os portadores do Hiǵger School Certificate. Além disso, alguns servidores da executive class conseguem, mediante prestação de concurso, forçar as portas da classe superior. Como o inglês continua a pensar que é mais importante, no que tange aos altos funcionários, possuir mais conhecimentos gerais do que técnicos, sòmente $20 \%$ dos dirigentes saem daquela classe. Pode dizer-se que, enquanto as escolas particulares ministrarem instrução geral de nível elevado, pràticamente a classe administrativa se protegerá contra uma possível invasão de indivíduos oriundos da pequena burguesia ou das camadas populares.

A Civil Service Commission, composta de três membros principais, nomeados diretamente pela Coroa, é que preside ao recrutamento de candidatos às quatro classes do Home Service (sinônimo de Civil Service). Bem remunerados, êles são incorruptíveis e pouco sensíveis às influências políticas. Sua tarefa é vasta e árdua.

Conquanto ainda figurem, nos programas crganizados para os concursos, matérias clássicas, no sentido antigo, um lugar cada vez maior vai sendo atribuído às ciências econômicas e sociais. O concurso de admissão à administrative class, sabidamente, é muito "duro". Exige-se do candidato uma dissertação geral (essay, ccm duração de duas horas), após a qual terá êle de resumir em 300 palavras difícil texto de autor inglês do século XIX (o précis, cuja duração é de uma hora) e responder sintética e objetivamente ã três questões 
sôbre assuntos da atualidade (o present day, que dura duas horas). Finalmente, tem de submeter-se ao viva voce test, a célebre interview, que data, aliás, de 1917. Além disso, deve optar entre algumas das disciplinas lecionadas nas universidades. O concurso para recrutamento de funcionários de outras classes segue as mesmas especificações, porém versa sôbre matérias mais fáceis.

Uma vez admitido, não recebe o novo funcionário treinamento profissional. Êste é feito no próprio serviço e êle tem como prcfessôres seus próprios superiores hierárquicos. Em uma palavra: êle tem de safar-se como puder. Poderá, no entanto, aperfeiçoar-se na técnica administrativa freqüentando o Institute of Public Administration, fundado em 1922 por iniciativa de um grupo de altos funcionáric's. Êsse instituto não é pròpriamente uma escola, mas um lugar de reunião para todos os que se interessam pela coisa pública. Ali se realizam conferências, debates e todos os anos um júri formado por cidadãos escclhidos entre os freqüentadores da instituição atribui um prêmio ac autor da melhor monografia sôbre assunto administrativo.

Terminado o estágio probatório, é o servidor efetivado em seu cargo.

Como acabamos de ver, entre as duas guerras mundiais a seleção do pessoal era rigorosa mas a formação administrativa, empìricamente feita, deixava a desejar. Não cbstante uma inegável democratização, as castas sociais em grande parte ainda subsistiam na administração inglêsa. A Grã-Bretanha ainda não era a nação igualitária - no bom sentido - em que se transformou a partir da segunda grande guerra.

O conflito sangrento que durou de 1939 a 1945 obrigou aquêle país a mobilizar todos os seus recursos, principalmente os recursos humanos e o ccmpeliu a ampliar as atribuições do Estado, de modo que a Administração cresceu e novos problemảs surgiram a reclamar solução, Não sòmente grande número de servidores civis reservistas fôra convocado para o serviço ativo como também as novas entidades criadas para atender às necessidades da guerra exigiam pessoal dirigente e burocrático. Reccrreu então o Govêrno aos professôres universitários. Mediante um exame oral (interview), baseado na formação geral de cada um, eram êles nomeados a título precário para a administrative class (temporary administrative civil servants). Isso, no que toca aos dirigentes, pcrque em relação ao pessoal subalterno nem exame houve. Tudo isso tinha caráter provisório. Cessada a tempestade, no entanto, cumpria reorganizar em bases sólidas. Essa necessidade de reorganização coincidiu com a chegada ao poder do Labour Party, que já antes da guerra tivera oportunidade de dirigir numerosas críticas ao Civil Service. Atacava particularmente a administrative class, na qual reprovava, não sem razão, como vimos linhas atrás, o fato de constituir uma casta fechada, que se recrutava em grande parte entre os ex-alunos das Public Schools. Negava, principalmente, o valor do viva voce test, porque êste dava muita importância à cultura geral e quase nenhuma às questões científicas e técnicas; dava margem à concessão de privilégics aos filhos de famílias de destaque em detrimento do inglês mdio, mais modesto e intelectualmente menos brilhante, porém muito mais sensato. 
Os elementos extremadcs do Labour Party preconizavam até a extinção das Public Schools, frequientadas por pessoas das classes abastadas; alguns reclamavam a unificação da classe administrativa, na qual se fundiriam tôdas as categorias do Civil Service e onde a promoção se faria por merecimento.

Pragmáticos e tradicionalistas, os inglêses, sob a influência das idéias trabalhistas, instituiram, ao lado de uma prova versando sôbre os conhecimentos dos candidatos, um exame psicológico por meio de testes para aferir-se-lhes as qualidades pessoais. Baseia-se esta prova no sistema utilizado nos Estados Unidos, onde não se recrutam necessàriamente os melhores, mas onde se procura selecionar os elementos, ainda que de valor médio, que se afigurem logo à primeira vista em condições de desincumbir-se de determinadas tarefas. O americano não recruta por meio de concursos cu provas baseados na cultura geral ou no conhecimento de certas técnicas, mas utilizando métodos de psicologia aplicada. O inglês, todavia, conquanto pouco a pcuco se vá encaminhando no sentido da utilização de regras de psicotécnica no recrutamento do pessoal, continua a selecionar candidatos cuja eficiência não seja tão diretamente apurada, ccmo na América, mas cujo nível intelectual se considere adequado à função a preencher.

Se bem tenha declinado a influência da interview, esta maneira de selecionar ainda se mantém em diversos concursos. A transferéncia de uma classe para outra facilitou-se. A administrative class não é mais um privilégio dos jovens saídos das altas camadas sociais, tanto mais que os trabalhistas favoreceram o acesso, às universidades, dos filhos das classes trabalhadoras mediante a instituição de inúmeras bôlsas de estudos, da mesma forma, aliás, que possibilitaram a alunos menos afortunados, sempre através de bôlsas de estudos, freqüentar Public Schools. Ademais, visando a acabar com o privilégio de Oxford ou de Cambridge, os homens do Labour Party concorreram para a expansão de outras universidades, tais como as de Londres, Manchester, Birmingham, etc. . Atualmente, a London School of Economics, subordinada à Universidade de Londres, é a matriz de onde têm saído vários altc's funcionários civis de modesta origem.

Lançou-se a idéia de criar um Civil Service Staff College, onde os funcionários de 35 anos pelo menos deveriam obrigatòriamente fazer um estágio visando a adquirir formação profissional que os tornasse aptos a ocupar os postos mais elevados da hierarquia administrativa. Até o presente, porém, a idéia não se concretizou. Parece que alguns inglêses a ela se mostram hostis, preferindo o treinamento profissional no seio da própria Administração.

Mantendo as quatro classes do Civil Service, mas democratizando o ensino e facilitando a transferência de uma categoria para outra, parece que os inglêses agiram sàbiamente. Urge uma revolução, mas revolução nos espíritos, nos hábitos, na maneira de viver e não revolução a golpes de fuzil ou de decretos. Além disso, a utilização de testes psicológicos ao lado dos meios tradicionais de recrutamento revela-se uma excelente providência, que se integra nos modernos métodos de recrutamento aos quais os serviços públicos se vão aos poucos adaptando. 
Napcleão reformara a administração francesa. O treinamento do pessoal fazia-se nos próprios serviços. Esta situação continuou sob regimes seguintes. A Monarquia de julho, (1) no entanto, após vários estudos, elaborou projeto de criação de uma escola administrativa, onde se formariam os futuros altos funcionários do país, projeto que só se concretizou sob a Segunda República. Em março de 1848, CARNOT, ministro da instrução pública do regime nascente, furdou uma escola de administração cuja estrutura e programa se basearam em estudos prccedidos, neste sentido, no govêrno de LouIs-PHILIPPE.

Abalada pela aspereza das lutas partidárias, essa nova escola, que funcionava a contento geral, desapareceu menos de dois anos após sua criação.

Que resultou de tão desastrada medida? Muito simplesmente, como escreveu com propriedade M. JEAN Chevalier em seu livro Organização do Trabalho, "preferiu-se antes elevar os diplomados ao mandarinato do que preparar os funcionários para as suas funções. A máquina de fazer eunucos de que fala PROUDHON passou a jorrar matemáticos e letrados a disputar indistintamente todos os cargos, sem a preocupação de adaptar-se a nenhum e, em conseqüência, tem-se cada vez menos chefes à altura de suas tarefas, as quais se tornam mais e mais pesadas à medida que adquire maior complexidade o funcionamento da máquina administrativa."

De qualquer maneira, durante quase um século, o Estado não se preocupou muito, pelo menos a sério, com a questão e a iniciativa privada teve que suprir sua falta nesse domínio.

Assim foi que, após a derrota de 1870 , a fim de obviar a ausência de formaçãc profissional dos servidores civis, indivíduos de recursos fundaram em Paris a Escola Livre de Ciências Políticas, familiarmente denominada "Science Po". Gerações de diplomatas, assessôres do Conselho de Estado, inspetores de finanças saîram dêsse estabelecimento, mas, relativamente, muito poucos dos ocupantes de cargos de direção das repartições ministeriais por lá passaram. É que, por sua própria essência, aquela escola recrutava seus alunos sobretudo nas classes mais favorecidas. Ela desempenhava papel análogo, pelo menos no que dizia respeito ao recrutamento de funcionários qualificados dos grandes corpcs administrativos (Conselho de Estado, Tribunal de Contas, Corpo Diplomático, etc.), ao de Oxford e Cambridge em relação aos candidatos à administrative class inglêsa.

Recrutados por concurso, os outros integrantes do funcionalismo público faziam seu treinamento no próprio serviço, sob a condição de alguns freqüentarem cursos universitários ou roturnos a fim de aperfeiçoarem sua bagagem intelectual ou mesmo técnica.

Para sermos exatos, devemos acrescentar que entre as duas guerras o desenvolvimento de certos serviças de ordem econômica permitiu aos laureados

(1) Chama-se Monarquia de julho ao regime instituído por LouIs PHILIPPE e que acarretou a asoensão dos Orléans, em substituição aos Bourbons, restaurados em conseqüência da queda de NAPOLEÃo (N.R.). 
da Escola de Altos Estudos Comerciais de Paris se instalarem brilhantemente em cargos administrativos de direção.

Depois da segunda guerra mundial a situação existente foi logo tida como insustentável. O decreto de 9 de outubro de 1945, que dispôs sôbre a reforma da administração, acentua: "Nossas universidades não dão a devida importância ao ensino das ciências políticas e sociais. Não existe qualquer preparação para o exercício da função pública... Os jovens redatores (oficiais administrativcs) ficam durante anos incumbidos de tarefas subalternas incompatíveis com sua capacidade e cultura. Sua formação profissional ressente-se com isso e êles correm o risco de, nessa situação, perder o espírito de iniciativa.

Feito o diagnóstico, a lei citada indica os remédios. Quais?

1..$^{\circ}$ Criação de várics institutos de estudos políticos encarregados de complementar o ensino das ciências sociais, administrativas e econômicas dado em algumas faculdades e de familiarizar os alunos com os métodos de trabatho de uma administração digna dêsse nome.

Aparecem êsses institutos como uma espécie de escolas de primeiro grau da função pública, onde os estudantes aprenderão a evolução política, as possibilidades econômicas e a estrutura social de seu país. Como declara com propriedade M. GiLbert Tixier, no pequeno trabalho intitulado $A$ formação dos quadros dirigentes do Estado na Grã-Bretanha e em França: "os institutos deverão equacionar os problemas para os quais a Esccla Nacional de Administração indicará as soluções adequadas".

$2^{\circ}{ }^{\circ}$ Instituição de uma Escola Nacicnal de Administração, que se deverá considerar mais um centro de estágio e formação profissional do que uma escola no sentido comum. Compor-se-á de três seções:

a) Negócios Exteriores;

b) Administração Geral;

c) Administração Sccial.

O primeiro ano é todo de estágio, visando a desenvolver nos que ali se iniciam - na sua maioria jovens recém-saídos da Universidade, principalmente dos institutos de estudos políticos - um senso humanístico. Êsse estágio seria feito na província, na África do Norte, ou no estrangeiro para os alunos da Seção de Negócios Exteriores.

Os dois anos seguintes conjugam um curso teórico sob a forma de conferências com novos estágios destinados à realização de trabalhos práticos. Um exame final encerra o ciclo de três anos passados na Escola. Os candidatos recebem, então, uma lotação definitiva.

Observemos, igualmente, que a Escola Livre de Ciências Políticas se transfcrmou no Instituto de Estudos Administrativos de Paris, que, de certa forma oficializado, continua a preparar jovens que se destinam ao Conselho de Estado, ao Tribunal de Contas, à Inspeção de Finanças e ao Corpo Diplomático.

3. ${ }^{\circ}$ Fundação de um Centro de Altos Estudos Administrativos, destinado ao aperfeiçoamento de funcionários, com o fim de prepará-los para o exercício das mais altas funções públicas, ou, mesmo, pô-los "em condições de 
dirigir e supervisionar as emprêsas industriais cu comerciais controladas pelo Estado.

A França compreendeu, pois, que não basta o título de bacharel ou doutor para ocupar cargos de nível superior na Administração. Cumpre formar especialistas e o Centro de Altos Estudos Administrativos se encarregará de dér acs funcionários ali admitidos uma visão de conjunto das tarefas da Administração e das atribuições do Estado.

Êste Centro, que não é pròpriamente uma escola no sentido amplo do têrmo, divide-se igualmente em três seções:

a) Seção Geral;

b) Seção dos Territórios de Além-Mar;

c) Seção do Setor Nacionalizađo.

$\mathrm{Na}$ primeira seçãc, estudam-se as questões gerais pertinentes à administração do Estado e aos diversos serviços públicos da metrópole. Na segunda, procede-se ao exame dos problemas políticos, econômicos, sociais, intelectuais e religiosos decorrentes da administração dos territórios ultramarinos integrantes da União Francesa. Na terceira e última seção, examinam-se os métodos mais apropriados à atividade industrial do Estado.

No intuito de prevenir uma eventual especialização dos estudos, o que iria de encontro ao fim visado, os pontos mais importantes foram objeto do trabalho em comum dos alunos distribuídos pelas três seções.

A opinião pública francesa, de modo geral, tem acolhido bem a criação dos institutos de estudos políticos. Tem-se mostrado mais reservada, porém, no que toca à necessidade de criação, simultâneamente, de uma Escola de Administração e de um Centro de Altos Estudos Administrativos. Parece a alguns que aquêles que já cursaram três anos na Escola Nacional de Administração não têm grande ccisa a aprender por volta dos quarenta anos no Centro de Altos Estudos Administrativos e que, por conseguinte, a fundação dêste era inútil. Outros, sobretudo dentre os alunos da ex-Escola Livre de Ciências Políticas, que ainda lamentam sua transformação no Instituto de Estudos Administrativos de Paris, negam o alegado benefício da criação de uma escola de administração oficial. Muitos, ao contrário, proclamam a excelência da instituição de um centro como o de Altos Estudus Administrativos.

Destas várias opiniões, pode concluir-se que, de qualquer maneira, o público francês deseja que os altos funcionários do Estado, bem assim os de grandes corpos administrativos especializados recebam uma formação profissional aprofundada, de preferência em um dos estabelecimentos de ensino superior especializados em ciências políticas, sociais, administrativas e econômicas.

\section{IV}

E na Bélgica? Antes do Estatuto de 2 de outubro de 1937, o recrutamento dos servidores do Estado se fazia da maneira mais empírica. Cada repartição recrutava seus próprios empregados sem que nenhuma regra fixa presidisse a êsse recrutamento. Não havia qualquer entrosamento entre os departamentos ministeriais e cada um dêles admitia seu próprio pessoal me- 
diante os mais variados critérios. Reinava c mais completo arbítrio. Assim é que em algumas repartições o ingresso se fazia por meio de concurso, ao passo que em outras - às vêzes no mesmo órgão ministerial - por favoritismo. No que tuca à formação profissional de seus servidores, bem pouco se importava a Administração com ela... A promoção às classes superiores se fazia por antiguidade, favoritismo, arranjo ou política, o que contribuiu bastante para desprestigiar a função pública.

Para obviar êste estado de ccisas, M. CAMU, Comissário da Reforma Administrativa, a quem se deve o Estatuto de 2 de outubro de 1937, classificou os servidores do Estado em quatro categorias, criou o cargo de secretário de administração, reorganizou a carreira de redator e suprimiu vários outros cargos . guintes:

Os critérios básicos desta nova classificação, em resumo, foram os se-

$\left.1 .^{\circ}\right)$ os servidores da primeira categoria, ou funcionários, são nomeados pelc Rei e incumbem-se de trabalhos de administração superior;

$2^{\circ}$ ) os da segunda categoria são nomeados pelo Ministro a quem o Rei delegou essa competência e colaboram diretamente com os funcionários superiores, executam as decisões ou thes controlam a execuçãc;

$3^{\circ}$ ) os das terceira e quarta categcrias são nomeados pelos chefes administrativos a quem o Ministro delegou êsse poder, cabendo-lhes executar serviços estatísticos e de rotina. No que concerne à última categoria, o serviço é em sua maioria puramente material.

Um decreto complementar, de 30 de março de 1939, especifica quais os servidores que devem integrar cada uma dessas quatro categorias.

$\mathrm{Na}$ primeira grupam-se os funcionários de nível mais elevado: diretores, inspetores, chefes de divisão e de serviço, secretárics de administração e, evidentemente, os cargos especializados do mesmo escalão.

Os subchefes de serviço (cargo antes suprimido e depois restabelecido em 1846), os redatores e assemelhados foram classificados na segunda categoria; os escriturários e dactilógrafos na terceira; o pessoal de portaria (porteiros, serventes, etc. ) na quarta. Posteriormente, criou-se um quadro técnicoprofissional, que agrupa os técnicos, artesãos e operários cujos cargos correspondem, segundo a posiçãci hierárquica reservada a seus titulares, aos nî̀eis do pessoal administrativo.

Para efetuar sua classificação, M. CAMU, sem desprezar estudos anteriormente feitos sôbre a matéria, baseou-se principalmente na situação existente no Civil Service inglês, já aqui examinada, assim como nas subdivisões existentes no próprio ensino belga: ciclo de estudos primárics, ciclo de estudos médios de grau inferior e de grau superior e ciclo de estudos superiores.

A administrative class tornou-se a primeira categoria; a do pessoal de direçãc, isto é, funcionários no sentido estrito do têrmo. Em princípio, o acesso a êsses cargos seria reservado aos portadores de diplomas de curso superior.

A executive class constituiu a segunda categoria, grupando os servidores incumbidos de executar as decisões ou de controlar-lhes a execução. Em prin- 
cípio, sòmente os portadores de certificado de conclusão de curso médio de grau superior (humanidades e cursos equivalentes) poderiam a êles ter acesso.

A clerical class, constituindo a quarta categoria, compreendia aquêles que houvessem concluído curso médio de grau inferior ou outro equivalente. Executariam trabalhos administrativos de rotina, de ordem preponderantemente material.

Finalmente, a copying and shorthand, a quarta categoria, gruparia aquêles que, não tendo ido além da escola primária, executariam serviço essencialmente material.

Essa matéria de classificação de funções tinha sido examinada anteriormente repetidas vêzes e as soluções preconizadas eram um pouco diferentes. Assim é que c pessoal se classificava em apenas três categorias: pessoal de direção, pessoal executivo e pessoal auxiliar. Quanto às exigências de diploma para o acesso a alguns cargos, eram menos rigorosas do que as estabelecidas no atual estatuto dos servidores públicos.

Dêsses vários estudos, M. CAMU adotou o princípio da classificação do pessoal em categorias, a exigência de diploma para pleitear emprêgo público e a criação do cargo de secretário de administração, inicial da primeira categoria e reservado aos universitários ou assemelhados.

Incontestàvelmente, a adoção do Estatuto de 2 de outubro de 1937 acabou, em parte, com a anarquia reinante na vida administrativa. Todavia, as conseqüências políticas, sociais e econômicas da segunda guerra mundial, quando o referido estatuto mal entrara em vigor, modificaram profundamente a estrutura da Administração belga. Era preciso regularizar a situação, nos váricis cargos, de numerosos servidores temporários, admitidos em sua maioria sem prova de habilitação. Novos serviços e cargos foram criados. Criticavase a subdivisão em categorias. Pessoas credenciadas consideravam, com razão, aliás, que a classificação dos cargos em três categorias seria suficiente. A questão da exigência de um diploma específico para acesso a tal ou qual categoria fêz correr muita tinta e muita saliva. Os sindicatos, particularmente, se opunham a tal exigência, tanto mais quanto consideravam a formação profissional do servidor público mais ou menos organizada.

Recrutar ùnicamente à base do nivel intelectual de cada um poderia aprofundar - como o atesta o exemplo da Inglaterra e até o da França - a divisão do funcionalismo em castas sociais. Para obviar êsse inconveniente, o Estatuto dispunha que mediante certos critérios de ordem administrativa e a realização de uma prova versando sôbre ccrnhecimentos gerais e técnicos qualquer servidor poderia transferir-se para uma categoria superior. Mas, como treinálos? No próprio serviço, segundo métodos puramente empíricos, rotineiros? $\mathrm{Ou}$ criando escolas, permitindo-lhes a frequiência a determinados cursus?...

Do ponto de vista do ensino especializado, que existia quando foi promulgado o Estatuto?

Já de longa data vinham as universidades instituindo cursos especiais de ciências políticas, administrativas e sciciais, de natureza puramente científica e que eram considerados mais como complementação do curso de Direito do que como de preparação para o serviço público. A matéria ali ministrada se dividia por dois ou três ancs e o diploma que coroava a conclusão daqueles 
cursos não conferia qualquer vantagem especial aos seus portadores, donde a reduzida freqüência aos mesmos. Além disso, fixando - um tanto arbitràriamente, à época - em quatro anos a duração dos cursus superiores exigidos para o ingresso na primeira categoria dos servidores do Estado, excluia o Estaiuto os poucos universitários que poderiam, em virtude de seus estudos especializadc's, considerar-se os mais qualificados para ocupar cargos públicos de direção, quer dizer, justamente os aiplomados em ciências políticas ou administrativas. Era um êrro. Era correr o risco de estancar na fonte, nas próprias universidades, o único curso - cum exceção, talvez, do de doutorado em direito - que preparava pessoal qualificado para o alto funcionalismo não técnico, isto é, para os postçs que não exigem diploma de médico, veterinário, engenheiro, agrônomo, etc.. Compreendendo o perigo de tal critério, as universidades reagiram e reformaram o programa daqueles cursos.

A Universidade Livre de Bruxelas deu o exemplo. Em 1939 encetou ela a reforma da Esccla de Ciências Políticas e Sociais, a fim de, especificou-se, "permitir aos jovens aos quais fôr ccnferido o grau de licenciado em uma das seções da Escola, concorrer às provas instituídas pelo Estado para os candidatos ao serviço público, com um título equivalente, do ponto de vista da formação científica, aos outros graus de licenciados conferidos por nossas faculdades e escolas". Com êste objetivo, o programa dos cursos de licenciamentos ampliaram-se, estendendo-se, daí em diante, por quatro anos.

As universidades do Estado seguiram a mesma orientação. A Bélgica sofreu, então, a ocupação alemã. A 25 de novembro de 1942, apesar de uma. viclenta oposição, o Secretário Geral do Ministério da Instrução Pública baixava um decreto reformando os cursos de ciências políticas, sociais e administrativas instituídos junto às Faculdades de Direito de Liège e de Gand.

Uma única consideração presidiu a essa reforma: a de assegurar aos jovens que se dedicam a estudos de ciências politicas, sociais e administrativas preparação eficiente para as altas funções administrativas... Isto fci dito com tôdas as letras e constituiu a única justificativa do decreto em questão.

Depois da libertação do território belga, tal decreto foi anulado. Todavia, a $1^{\circ}$ de março de 1945 , outro decreto, do Regente, redigido em têrmc's quase idênticos, ratificou de jure a reforma surgida de facto em 1942 .

Freqüentar uma universidade custa caro. Não é coisa ao alcance de tôdas as bôlsas, pelo menos enquanto uma reforma mais democrática não se verificar no ensino. Assim, só uma minoria privilegiada se beneficiará das novas disposições em matéria de estudos políticos, sociais e administrativos. Devem jovens capazes, mas de poucos recursos, marcar passo em uma categoria inferior? Ou deverão êles arranjar-se sòzinhos para adquirir a cultura indispensável acs altos funcionários do Estado?

Não, seria anti-social e sôbre isto todos estão de acôrdo. Para obviar tal situação, alguns preconizam a criação de uma escola universitária de administração, sediada em Bruxelas, cujos cursos seriam seguidos por servidores altamente qualificados, integrantes da segunda categoria (redatores, subchefes de seção ou cargos correspondentes), candidatos aos carges de direção, para isso designados pelas respectivas repartições. 
Inútil acrescentar que, se adotada, semelhante proposta teria repercussões desastrosas não só do ponto de vista dos dinheiros públicos desnecessàriamente gastos, como do ponto de vista da justiça e da igualdade entre o pessoal.

$\mathrm{Na}$ realidade, os cursos de que se trata ocupariam forçosamente todo o dia $e$, em consequêência, o rendimento do trabalho dos servidores que tivessem de freqüentá-los se reduziria de muito, sobrecarregando, ao contrário, seus colegas, que teriam de suprir sua falta. Ora, isso seria uma flagrante injustiça, tanto mais quanto a designação de servidores para seguir tais cursos teria que obedecer a puro arbítrio. Além disso, os servidores integrantes da terceira categoria se sentiriam, com razãc, prejudicados pelo fato de não ter sido criada, paralelamente, uma escola semelhante para êles.

Acham uns que se deveria criar uma escola de administração tomando por modêlo a Escola Militar. O próprio autor destas linhas foi durante muito tempo partidário dessa fórmula, tendo mesmo chegado, há alguns anc's, a elaborar projeto de criação de uma instituição dêsse gênero, bem assim a fixar as modalidades de acesso e as vantagens que a conclusão do curso conferiria.

Naquela ocasião, imaginava eu a criação de uma escola superior do Estado, que abrangesse três anos de estudos, findos os quais estariam os diplomados habilitados a ocupar os cargos superiores que não exigissem especialização, comuns a tôdas as repartições ministeriais. Um quarto ano, todo dedicado a questões econômicas e financeiras, prepararia os candidatos para certas funções elevadas, não técnicas, porém mais especializadas, tais como inspetor de finanças, conselheiro ađjunto do orçamento etc.

Anualmente, determinado número de candidates seria admitido ao primeiro ano mediante concurso ao qual poderiam concorrer:

$\left.1 .^{\circ}\right)$ os servidores da segunda categoria que contassem pelo menos dois anos no cargo e fôssem considerados "bons"; valente.

$2^{\circ} .^{\circ}$ os detentores de um diploma de curso médio superior ou outro equi-

O concurso de admissão versaria sôbre as seguintes matérias: (redação e história da literatura), história geral, geografia política e econômica, aritmética geral e álgebra elementar. As provas seriam escritas e crais.

Direito, economia política, história das instituições políticas e administrativas, organização e doutrina administrativas constituiriam a base do curso nos três primeiros anos. Contabilidade, legislação comercial e financeira, doutrinas econômicas e suciais completariam o programa no quarto ano.

Os que terminassem o ciclo básico de três anos receberiam um diploma de habilitação para as funções de secretário de administração. Um determinado número de vagas dessas funções lhes seria reservado juntamente com outras postas em concurso para portadores de diploma universitário e, à medida que ocorressem as vacâncias, iriam sendo nomeados.

Sòmente aquêles que pretendessem atingir um cargo especializado não técnico e que para tanto houvessem obtido seu diplcma de habilitação com $7 / 10$ dos pontos, poderiam cursar o quarto ano. Se assim o desejassem, porque 
êsse ano de curso suplementar não thes conferiria qualquer vantagem além daquela de disputarem, em concurso, ccm alguma possibilidade de êxito, o cargo para o qual se preparassem.

Durante o curso, os alunos já pertencentes ao serviço público receberiam parte de seus vencimentos, ficando a parte não paga para custear as despesas do curso.

Tracei o esquema dêsse projeto apenas a título dcıumental. Hoje, por razões que exporei mais adiante, não sou mais partidário da criação dessa escola.

Em compensação, há os que se revelam francamente hostis à instituição de qualquer tipo de escola de Administração, entre êles o falecido M. HALEWIJCK DE HEUSCH, que foi 1. $^{\circ}$ Secretário Permanente para o Recrutamento, o qual assim justificava o seu ponto de vista:

"Em nosso país" - escreveu êle - "a instituição de uma escola dêsse tipo não corresponde a qualquer necessidade. O ensino aqui ministrado é bastante adiantado e não é difícil encontrar candidatos convenientemente preparados para todos os setores da primeira categoria da Administração. Pode mesmo dizer-se que, pela diversidade de suas faculdades e escolas, o nosso sistema educacional atende bem melhor do que um instituto central a tôdas as necessidades dos serviços públicos, muito complexos e diversificados; êle tem uma universalidade que não se conseguirá num estabelecimento único de finalidade fatalmente limitada. (2)

De modo geral, menospreza-se o ensino superior noturno. Ignorância da parte de uns, desprêzo universitário ou espírito pequeno burguês da parte de outros, que confundem ensino ncturno com "escola dominical". E no entanto, quantos serviços o ensino noturno tem prestado à Administração e seus servidores!

Após a primeira guerra mundial, as províncias e as comunas compreenderam que era preciso dar formação profissicnal a seus servidores, a fim de integrar bons quadros. Daí a criação de cursos de ciências administrativas, que, modestos a princípio, foram-se desenvolvendo gradativamente a estão hoje em grande voga entre o funcionalismo das províncias e das comunas.

Estes cursos, dados depois do expediente, geralmente a partir das dezessete horas, não integram, no entanto, o ensino supericr noturno.

Foi por iniciativa de M. Albert Henry, advogado na Côrte de Apelação de Bruxelas, diretor geral honorário do Ministério da Agricultura e exprofessor do Instituto Superior de Comércio da Cidade de Bruxelas, que a direção dêste estabelecimento de ensino superior noturno acrescentou, há uns vinte anos atrás, uma seção administrativa à seção comercial e financeira já existente.

A criação dessa seção tinha um fim eminentemente scicial: oferecer aos empregados do Estado e dos órgãos a êle subordinados, que pela necessidade de ganhar a vida se vissem impossibilitados de seguir cursos superiores, o meio

(2) Cf. O Recrutamento dos Servidores do Estado (Serviço de Publicidade, Bru- 
de ampliar e consolidar seus conhecimentos permitindo-lhes, dessa fcrma, corrigir as desigualdades da sorte.

A nova seção alcançou logo o maior sucesso e não tardou a ser autorizada pelo Govêrno a conferir o grau de bacharel em ciências administrativas.

Esta autorização foi dada em 25 de agôsto de 1927 e menos de um ano depois o Instituto Superior de Comércio de Bruxelas estava habilitado a conferir o grau de licenciado em ciências administrativas. Quando, pcr decreto de 17 de junho de 1934, o Estado encampou o Instituto, desprezou por completo os cursos administrativos ali existentes, limitando-se a permitir-lhes a expedição de diplomas de candidaturas e licenciatura em matérias do curso comercial.

A fim de sanar essa negligência, um decreto real de 17 de setembro de 1934 autorizou a concessão do grau de licenciado em ciências comerciais e administrativas. Mistura estranha, justificável até certo ponto, mas que prejudicava os interêsses dos que, seguindo os cursc's da seção administrativa, se viam obrigados, para obter uma licenciatura, a sobrecarregar-se de noções sôbre matéria comercial, em detrimento de um conhecimento mais aprofundado das matérias jurídicas e administrativas.

Visando a contornar tal dificuldade, a direção do Institutc mantém uma seção de altos estudos administrativos, que, após três anos de curso, possibilita aos que o concluem a obtenção de um diploma especial em ciências administrativas. Hoje, os curscis desta seção comportam cinco anos de estudos e os diplomados que já estejam a serviço do Estado podem, por meio de certas disposições administrativas, concorrer às provas para secretários de administração tanto quanto os diplomados pelos cursos diurnos. Mas só após anos de luta se logrou essa vitória.

È justo se assinale, de passagem, que quase todos os diplomados por esta seção se vêm saindo muito bem nos concursos a que se submetem para c acesso à categoria de funcionários (chefes de seção, secretários de administração) perante o Secretariado Permanente do Recrutamento, o que prova a excelência do ensino ali ministrado.

Inspirando-se no precedente da seção de Altos Estudos Administrativos, um Hoger Instituut voor Bestuurswetenschappen (que mais tarde passou a denominar-se Hoger Instituut voor Besturr en Handelswetenschappen) surgiu em 1938. A exemplo da seção que the serviu de modêlo abrange êle também cinca anos de estudos e igualmente confere um certificado de conclusão de curso, que, por sua vez, concede aos seus portadores as mesmas vantagens reconhecidas, sob o ponto de vista do acesso à primeira categoria, aos diplomados pela Seção de Altos Estudos.

Fci a existência dêsse curso administrativo superior noturno que me fêz abandonar, pouco a pouco, a idéia de propor a criação de uma escola de administração.

- Se não me parece justo que se exija diploma para a prestação de concurso para uma das categorias inferiores, sejam elas três ou duas, salvo, evidentemente, em relaçãc a cargos especializados como o de enfermeira, assistente social, etc. - não sou, por isso, menos partidário da exigência do diploma de ensino superior, diurno ou noturno, para o acesso à primeira categoria, com 
o curretivo do concurso, tal como atualmente. Isso permitirá, aliás, que se desenvolva, em algumas grandes cidades de província, um ensino administrativo superior noturno. Parece que a cidade de Antuérpia já se entregou a essa tarefa.

Hoje, ao contrário, inclino-me a considerar que o treinamento, em relação às categorias inferiores, deve ser feito pela Administração mesma, se necessário durante as horas de expediente. Já existem precedentes a respeito, principalmente na administração alfandegária.

\section{V}

Concluindo estas considerações e com base na ligeira análise que acabei de fazer da situação existente na Inglaterra, França e Bélgica, pçe afirmar-se que o Estado deve selecionar o pessoal que ingressa ao seu serviço. A não ser quando se trate de cargos especializados, não se deve obrigatòriamente exigir diploma para o recrutamento do pessoal subalterno.

Relativamente aos cargos de direção, uma formação universitária é desejável. A sua falta, conhecimentos equivalentes adquiridos através do ensino administrativo superior noturno, ou qualquer outro. Para admissão, a posse de um diploma de curso superior deve ser exigida, independentemente de concurso ou de prova de habilitação. E aqui colocaria os diplomas de curso noturno no mesmo pé de igualdade com os de curso diurno.

Os servidores de categorias inferiores, no entanto, quando investidos no cargo de redator ou assemelhadc, e se satisfizerem a condição de merecimento e antiguidade, poderão prestar a prova de habilitação à primeira categoria e, em caso de êxito, ser nomeados da mesma maneira que os portadores de diplomas, como, de resto, se faz atualmente nos países que acabei de passar em revista.

\section{SUMMARY \\ ABOUT THE RECRUITING AND PROFESSIONAL TRAINING OF CIVIL SERVANTS}

The author describes the systems of recruiting and training in the United Kingdom, in France and in Belgium, and, incidentally, stresses the importance of a distinction in four classes according to background and functions as is current in the former country.

His main conclusions are that initial entry should rest mainly, if not solely, on general knowledge and response to psychotechnical tests. All specialised training and, in general, professional grounding, should be the sole responsibility of the Civil Service itself. 